\title{
Evaluation of radar-based precipitation estimates for flash flood forecasting in the Three Gorges Region
}

\author{
ZHE LI ${ }^{1}$, DAWEN YANG ${ }^{1}$, YANG HONG ${ }^{2}$, YOUCUN QI ${ }^{3}$ \& QING CAO ${ }^{4}$ \\ 1 Department of Hydraulic Engineering, Tsinghua University, Beijing 100084, China \\ zli09@mails.tsinghua.edu.cn \\ 2 Department of Civil Engineering and Environmental Science, University of Oklahoma, Norman, OK 73072, USA \\ 3 Cooperative Institute for Mesoscale Meteorological Studies, University of Oklahoma, and NOAA/OAR/National \\ Severe Storms Laboratory, Norman, OK 73072, USA \\ 4 Enterprise Electronics Corporation, Norman, OK 73072, USA
}

\begin{abstract}
Spatial rainfall pattern plays a critical role in determining hydrological responses in mountainous areas, especially for natural disasters such as flash floods. In this study, to improve the skills of flood forecasting in the mountainous Three Gorges Region (TGR) of the Yangtze River, we developed a first version of a high-resolution $(1 \mathrm{~km})$ radar-based quantitative precipitation estimation (QPE) consideration of many critical procedures, such as beam blockage analysis, ground-clutter filter, rain type identification and adaptive Z-R relations. A physically-based distributed hydrological model (GBHM) was established and further applied to evaluate the performance of radar-based QPE for regional flood forecasting, relative to the gauge-driven simulations. With two sets of input data (gauge and radar) collected during summer 2010, the applicability of the current radar-based QPE to rainstorm monitoring and flash flood forecasting in the TGR is quantitatively analysed and discussed.
\end{abstract}

Key words weather radar, precipitation, distributed hydrological model, flood forecasting

\section{INTRODUCTION}

Accurate measurement of precipitation at relevant spatial and temporal scales is critical to the reliable simulation of hydrological responses, and is particularly important to the prediction of natural hazards linked with precipitation extremes, such as floods and landslides. During the past decade, as an alternative technique, weather radar has been recognized for its great potential to provide quantitative precipitation information with high resolution in both space $\left(\sim 1 \mathrm{~km}^{2}\right)$ and time (5-15 min) scales (Berne and Krajewski, 2012) compared to conventional ground gauges. Usually, the hydrological modeling will suffer from input uncertainties caused by unrepresentative spatial sampling of gauges with low density or their non-optimal layout (Volkmann et al., 2010), but in contrast, weather radar is able to capture the precipitation spatial pattern, and thus help to improve the performance of hydrological prediction (Yang et al., 2004).

Generally speaking, the complex terrain in mountainous area often induces intensified rainfall with great spatio-temporal variability due to the orographic effects (Buytaert et al., 2006), and for local hydrological response, the topography may also increase total floods volume as well as accelerate their concentration (Delrieu et al., 2009). Recent research has indicated that the gauge density in most mountainous watersheds cannot reach the minimum density that is recommended by the World Meteorological Organization (Mishra and Coulibaly, 2009). For these reasons, radarbased quantitative precipitation estimation (QPE) plays a unique role in storm monitoring and flood prediction over such complex terrain regions.

Now the network of China next generation radar (CINRAD) covers most of the country, but the studies focusing on applications of radar QPE products for flood forecasting and water resources management are limited. This study aims to propose an initial version of radar QPE algorithms in the TGR, and examine the applicability of the radar QPE to regional flood forecasting. For this purpose, a grid-based distributed hydrological model was established and calibrated as the regional modelling tool, taking two sets of input data (gauge data as well as radar QPE). With both datasets collected during 2010 summer, the performance of radar QPE for rainstorm monitoring and local flood forecasting in the TGR are evaluated and discussed. 


\section{DATA AND METHODOLOGY}

\section{Study area}

The study area, called the Three Gorges Region (TGR), is shown in Fig. 1. The total area of the TGR covers nearly $60000 \mathrm{~km}^{2}$, and the elevation ranges from 15 to $3090 \mathrm{~m}$. The main stream of the Yangtze River (the bold line in Fig. 1) stretches for $\sim 650 \mathrm{~km}$, and the Three Gorges Dam is located at the east end of this region (the square in Fig. 1). Because of the complex terrain in the TGR, there are many small tributaries (thin grey lines in Fig. 1), which directly drain TGRgenerated floods into the Yangtze main river. Generally, floods are always triggered by highintensity and long-lasting rainfall in summer, thus this study focuses on the flood season, which starts in June and continues until September.

\section{Gauge data}

Hourly rainfall data are available from 78 automatic tipping-bucket gauges (circles in Fig. 1), which are installed and operated by the China Three Gorges Corporation (CTGC). Data quality of the CTGC gauges is checked by comparing their accumulated daily rainfall with coincident daily records from the nearby China Meteorological Administration (CMA) gauges (four pairs of gauges are found in total). The result indicates that the correlation values between these two datasets are greater than 0.95 with averaged root-mean-square error (RMSE) of $\sim 2.5 \mathrm{~mm} /$ day, suggesting that the CTGC data have been collected with reasonable accuracy.

\section{Radar QPE}

In 2007, an S-band Doppler radar (the circle with a cross in Fig. 1), located at the centre of the TGR, was installed by the CMA. The radar (named WANXIAN) collects data every 6 min up to a maximum range of $460 \mathrm{~km}$ (we only use measurements within the range of $230 \mathrm{~km}$, due to the radar performance degradation at long range) operating at nine elevation angles ranging from $0.5^{\circ}$ to $19.5^{\circ}$. The range resolution is $1 \mathrm{~km}$ while the azimuth resolution is $1^{\circ}$; more details of radar parameters can be found in Li et al. (2014b).

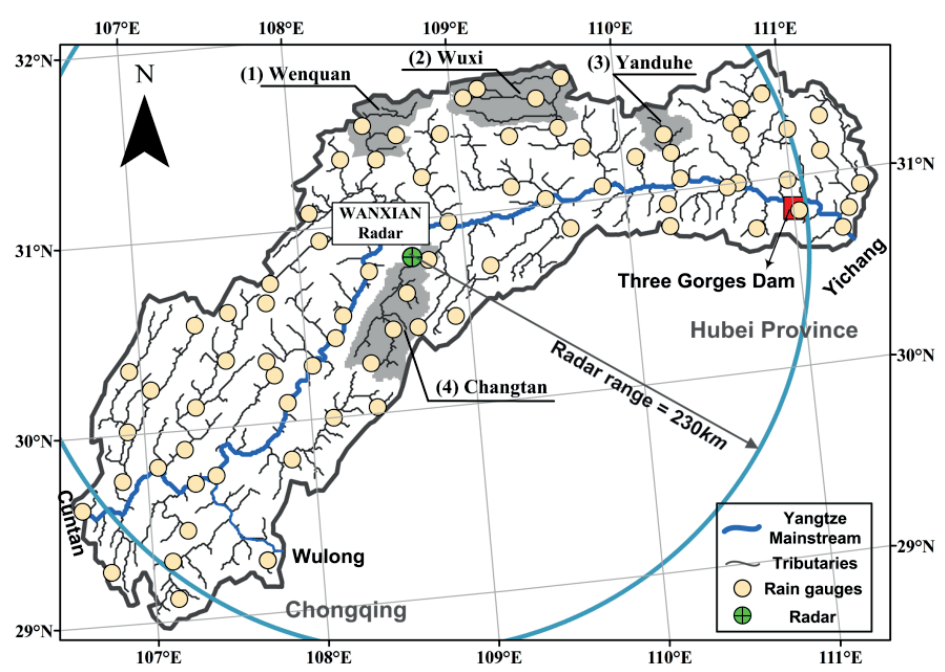

Fig. 1 Locations of raingauges and WANXIAN radar in the Three Gorges Region.

We developed the first version of rainfall $\mathrm{R}$ retrieval algorithms based on the single S-band radar. In brief, the major procedures for TGR radar QPE are summarized as follows:

(1) Beam blockage analysis: We use the classical beam propagation model combing the $100 \mathrm{~m}$ Digital Elevation Model (DEM) to map the severity of blockage (Kucera et al., 2004), and based on this result, the strategies to generate hybrid-scan reflectivity $\mathrm{Z}$ can be determined (Fig. 2(a)-(b)); 
(2) Ground clutter removal: a simple clutter filter utilizing Doppler velocity measurement is applied to remove the ground clutter. We identify the clutter contaminated radar bins as those with radial velocity around zero $( \pm 0.5 \mathrm{~m} / \mathrm{s})$ only within $50 \mathrm{~km}$ range, and assign zeroreflectivity to these bins to get the filtered reflectivity map;

(3) Rainfall type classification: Following the methodology proposed in the National Mosaic and the next-generation quantitative precipitation estimation (Q2) system (Zhang and Qi, 2010), we identify rainfall types based on the vertically integrated liquid water (VIL). If the VIL value is greater than the threshold (here default $=6.5 \mathrm{~kg} / \mathrm{m}^{2}$, as in the Q2 system, but its local value should be checked in future), then the pixel is classified as convective, otherwise stratiform is determined as the default (Fig. 2(c));

(4) Adaptive $Z-R$ relations and spatio-temporal resampling: based on rainfall types, different $Z-R$ relations are applied to the convective $(Z=300 R 1.4)$ and the stratiform $(Z=200 R 1.6)$ rainfall pixels. Ultimately, 6-min radar rainfall retrievals are integrated into hourly scale and then resampled into $1 \mathrm{~km}$ to generate the final product (Fig. 2(d)).
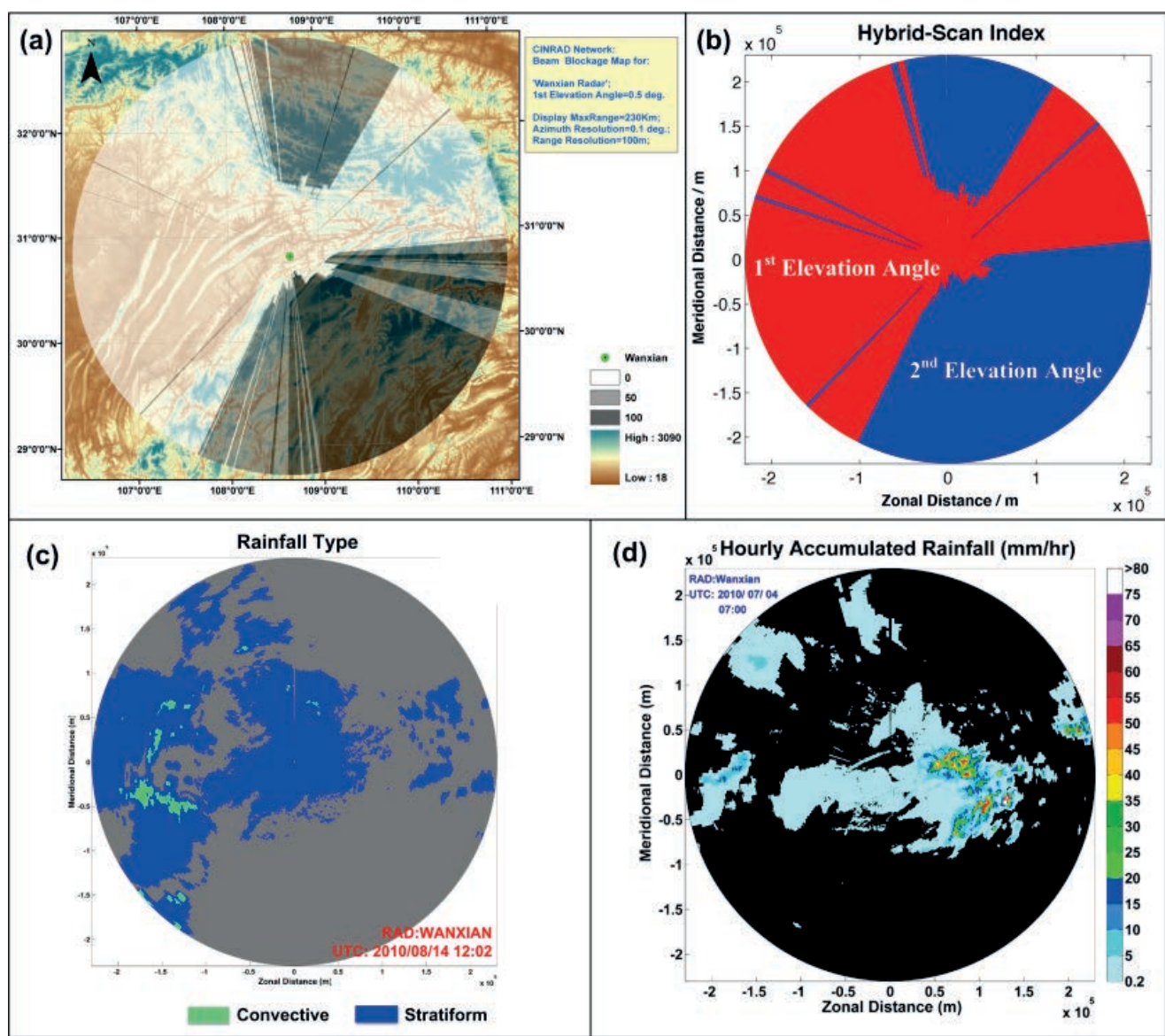

Fig. 2 Major procedures of radar QPE algorithms at the Three Gorges Region.

\section{Distributed hydrological model}

In this study, a distributed geomorphology-based hydrological model (GBHM; Yang et al., 2004) is applied to the TGR. GBHM takes advantages of the geomorphologic similarities to reduce the spatial-structure complexity within a grid, and characterize the catchment by the hillslope-stream formulation. In brief, GBHM includes the following components: a gridded discretization scheme, a sub-grid parameterization scheme, a hillslope-based hydrological model module, and a kinematic wave flow routing module. 


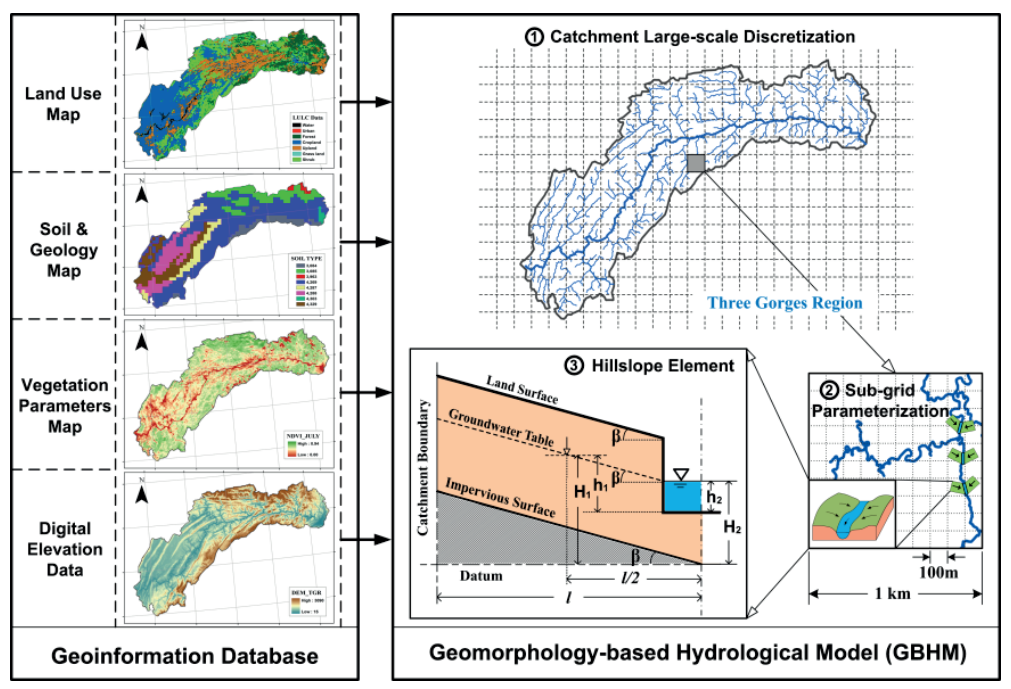

Fig. 3 Schematic diagram of GBHM for the Three Gorges Region.

Considering the computational capacity and the available regional geographical datasets, we construct GBHM of the TGR with a grid size of $1 \mathrm{~km}$. The geographic information is extracted from a number of global datasets, including the DEM, land use/land cover (LULC) data, soil type and normalized difference vegetation index (NDVI) products. The whole TGR is divided into 225 sub-basins, and grids within a sub-basin are classified into a series of flow intervals. Within a flow interval, grids are grouped into different categories of hillslope according to land cover types and topography, which are calculated from the geographical information data (Fig. 3).

The $1-\mathrm{km}$ forcing fields are interpolated from 78 CTGC raingauges using an angular distance weighting method, and other meteorological fields are interpolated from nearby CMA gauges with observations of wind speed, relative humidity and temperature. The TGR-GBHM is calibrated with 2004-2005 discharge records (collected in sub-basins, grey area in Fig. 1), and evaluation results show that this model is able to simulate streamflow of rivers in the TGR reasonably (Li et al., 2013). Therefore, we take this model to benchmark radar QPE into flash flood forecasting.

\section{RESULTS AND DISCUSSIONS}

\section{Distributed hydrological model}

With rain gauge measurements and radar observations during summer 2010 (July-September), first we compare point-scale gauge data with radar QPE at the pixel where the gauge is located. Table 1 summarizes the evaluation metrics for the point-scale comparison during 8 typical rainstorms in that summer. Over and underestimation occurs, but most of the correlation coefficients (CC) are greater than 0.60. The result indicates radar, as a remote sensing technique, suffers great estimation bias for point-scale rainfall observation.

Table 1 Statistics for 8 typical storm events during 2010 summer in TGR.

\begin{tabular}{llllll}
\hline $\begin{array}{l}\text { Date } \\
\text { (UTC Time) }\end{array}$ & $\begin{array}{l}\text { Duration } \\
\text { (hours) }\end{array}$ & $\begin{array}{l}\text { Max rain } \\
(\mathrm{mm})\end{array}$ & $\begin{array}{l}\text { Mean rain } \\
(\mathrm{mm})\end{array}$ & Bias & CC \\
\hline June 18 & 11 & 48.2 & 10.2 & 2.04 & 0.70 \\
July 3 & 13 & 45.4 & 16.8 & 1.18 & 0.35 \\
July 8 & 10 & 85.4 & 25.2 & 0.85 & 0.61 \\
July 17 & 9 & 98.2 & 14.3 & 0.94 & 0.87 \\
August 1 & 15 & 65.8 & 11.6 & 1.31 & 0.42 \\
August 14 & 21 & 131.2 & 58.7 & 0.72 & 0.68 \\
September 5 & 13 & 66.2 & 26.7 & 0.71 & 0.80 \\
September 9 & 21 & 114.6 & 33.1 & 0.63 & 0.87 \\
\hline
\end{tabular}


To take an in-depth look at point-scale radar estimates compared to gauge records, we select two cases for further discussion. The first event selected was a fast-moving rainfall system with a strong convective centre, and this convective-dominated event took place around 22:00 UTC on 3 July 2010 and lasted for 13 hours. The second one, which occurred on 9 September 2010 and started at around 02:00 UTC, lasting for about 21 hours, was a widespread and relatively uniform rainfall event. Figure 4 presents the event-accumulated rainfall comparison, and the gauge-radar data pairs are grouped by the range $(<50 \mathrm{~km}, 50-150 \mathrm{~km}$, and $>150 \mathrm{~km})$.

It is clear that, when the distance from radar increases, the radar rainfall estimate seems to be much more scattered and less correlated for both cases. Besides, this result also suggests that radar tends to overestimate rainfall (with relative bias of $30.2 \%$ ) during convective events while underestimating it (with relative bias of $-31.2 \%$ ) during stratiform rainfall events. Meanwhile, radar estimates within $150 \mathrm{~km}$ for the convective event are more scattered, but less biased, than those for stratiform events. On the whole, radar provides reasonable estimates of accumulated precipitation during rainstorms within $150 \mathrm{~km}$, which suggests radar data could provide valuable information for flood prediction at short-range regions in the mountainous TGR.
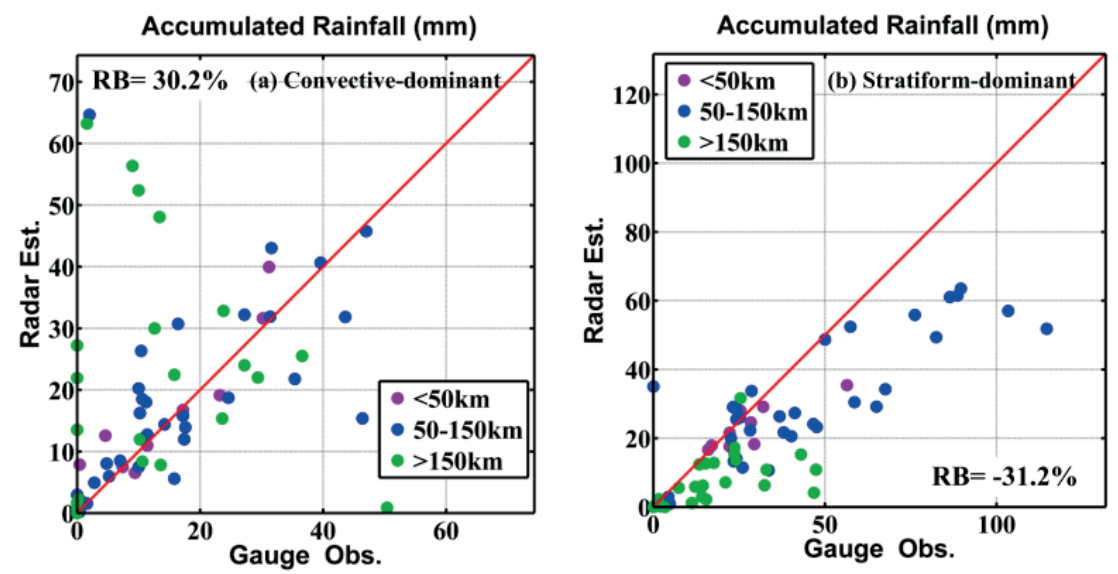

Fig. 4 Gauge observation compared with radar estimates during typical rainstorm events: (a) convective event; (b) stratiform event. RB represents the value of relative bias.

\section{Comparison of rainfall estimates at basin-scale}

With four selected sub-basins (called Wenquan, Wuxi, Yanduhe, and Changtan, respectively; see Fig. 1), we further compare the gauge interpolated and radar estimated rainfall at basin-scale, which plays a critical role in determining the basin-scale hydrograph pattern.

Generally, we find that the radar estimated rainfall is well correlated with gauge measurements at basin-scale, and most of the correlation coefficients (CC) for radar-gauge data pairs over all basins range from 0.70 to 0.94 . As for bias, radar estimation is dominated by positive bias (i.e. overestimation) while few cases show slight negative bias $(-15.6 \%$ to $-2.2 \%)$.

\section{Flood forecasting based on radar QPE}

Flood forecasting skills are compared by applying two sets of rainfall inputs (radar and gauge estimates) at four selected sub-basins of the TGR. Generally, radar-based simulation could give reasonable results at Wenquan, Yanduhe and Wuxi, and simulation by radar in Changtan basin is obviously affected by the ground clutter, showing unstable streamflow modelling results as simulated soil moisture is always saturated (figure not shown here). The results also suggest that, for flood forecasting, radar can provide additional useful information to help to capture some subtle features of local floods. 

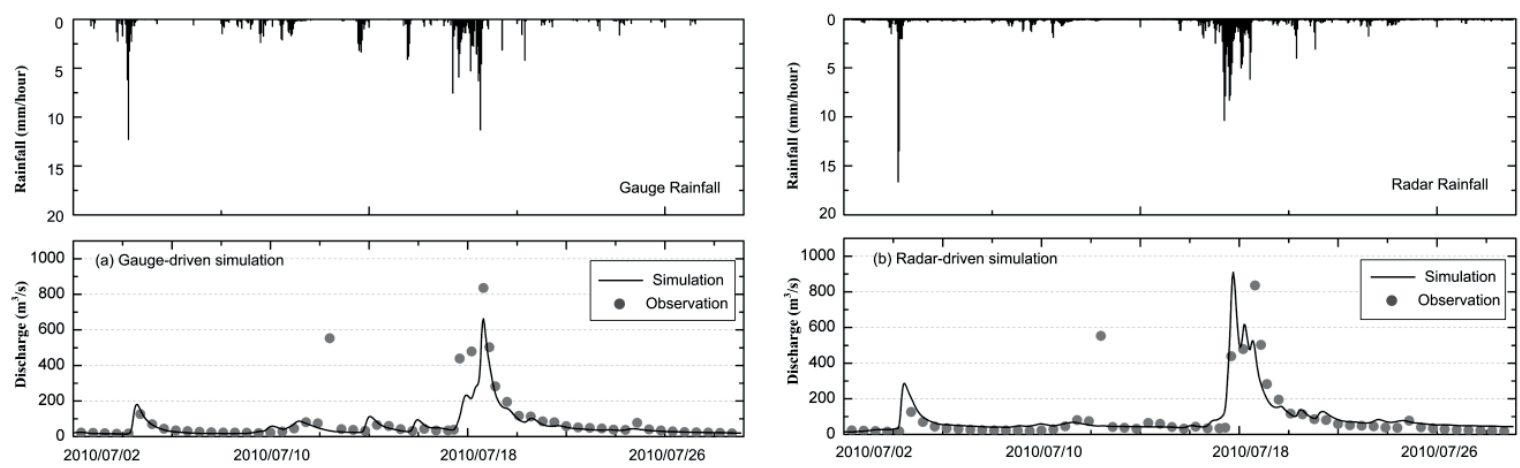

Fig. 5 Comparison of simulation by different rainfall inputs at Wenquan basin in 2010 July.
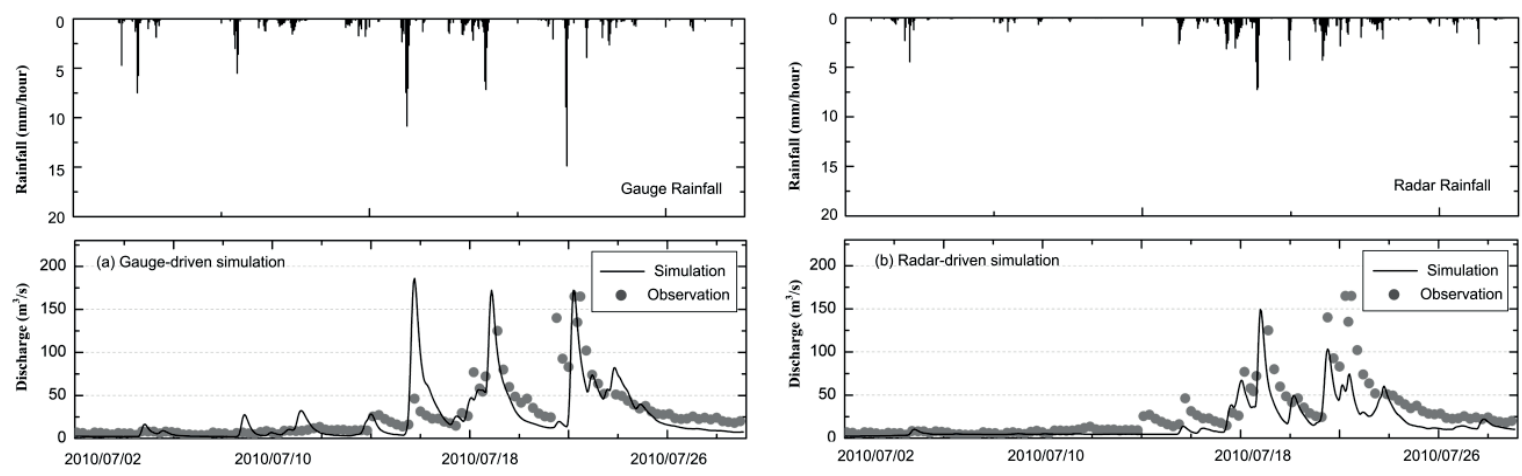

Fig. 6 Comparison of simulation by different rainfall inputs at Yanduhe basin in 2010 July.

Figures 5 and 6 compare the streamflow simulation results using two sets of rainfall input in July 2010 at Wenquan and Yanduhe basins, respectively. For Wenquan basin, it is clear that radar shows competitive performance compared with gauge-driven simulation. In the context of flood volume, radar gives a better modelling result during the flood events around 18 July. Combining the two simulation results, we also suspect the high flow record around 12 July could be caused by observation error.

For Yanduhe basin, radar also captures the key pattern of flooding processes in July. Different from gauge-driven simulation, the radar-based result eliminates an unrealistic flood peak around 16 July. With investigation of rainfall spatial maps during this event (not shown here), we find that this is caused by a localized rainstorm (scale $\sim 20 \mathrm{~km}$ ) occurred on the south side of the TGR, and is taken into rainfall mapping over the Yanduhe basin via the eight-neighbours interpolation scheme applied. This result is consistent with our previous results using storms tracking algorithms to decompose summer rainstorms in the TGR ( $\mathrm{Li}$ et al., 2014a), thus we conclude that radar will be very useful for localized flood forecasting in the mountainous area. For the flood event around 22 July, the underestimation by radar is perhaps caused by the uplift of radar beams at far range, which should be addressed by correction of the vertical profile of reflectivity (VPR) in future.

\section{CONCLUSIONS}

The study aims to quantitatively evaluate the applicability of weather radar estimated rainfall to rainstorm monitoring and flood forecasting in the TGR using a high-resolution distributed hydrological model. Results show that the radar QPE suffers larger uncertainty for point-scale rainfall estimation, while it can give reasonable results at the basin-scale. It is found that radar provides valuable information of rainfall mapping and flood forecasting at basins within $150-\mathrm{km}$ range. The analysis also suggests that, for flood forecasting, radar can provide useful spatial information to capture some subtle features of local floods, triggered by localized rainstorms. Future efforts should be made to deal with ground clutter and VPR correction, which cause trouble for radar-based flood forecasting in basins which are located at short and far range, respectively. 
Acknowledgements This research was supported by the National Natural Science Funds for Distinguished Young Scholar (Project No. 51025931) and the National Natural Science Foundation of China (Project No. 50939004).

\section{REFERENCES}

Berne, A. and Krajewski, W.F. (2012) Radar for hydrology: Unfulfilled promise or unrecognized potential? Advances in Water Resources 51, 357-366.

Buytaert, W., et al. (2006) Spatial and temporal rainfall variability in mountainous areas: A case study from the south Ecuadorian Andes. Journal of Hydrology, 329: 413-421.

Delrieu, G. et al. (2009) Bollène-2002 Experiment: Radar Quantitative Precipitation Estimation in the Cévennes-Vivarais Region, France. Journal of Applied Meteorology and Climatology 48, 1422-1447.

Kucera, P.A, Krajewski, W.F. and Young, C.B. (2004) Radar beam occultation studies using GIS and DEM technology: an example study of Guam. Journal of Atmospheric and Oceanic Technology 21, 995-1006.

Li, Z., Yang D., and Tian F., (2013) Flood Forecast of the Yangtze Three Gorges Region Based on Ground-Observed Rainfall. Journal of Hydroelectric Engineering (in Chinese), 32(1), 44-49, 62.

$\mathrm{Li}$, Z. et al. (2014a) Characterizing spatiotemporal variations of hourly rainfall by gauge and radar in the mountainous Three Gorges region. Journal of Applied Meteorology and Climatology 53, 873-889.

Li, Z. et al. (2014b) Radar-based quantitative precipitation estimate in the Three Gorges Region of Yangtze River. Journal of Hydroelectric Engineering (in Chinese), 33(3), 29-35.

Mishra, A.K. and Coulibaly, P. (2009) Developments in hydrometric network design: A review. Review of Geophysics, 47: RG2001.

Volkmann, THM., et al. (2010) Multicriteria design of rain gauge networks for flash flood prediction in semiarid catchments with complex terrain. Water Resources Research, 46: W11554.

Yang, D.W., Koike T. and Tanizawa, H. (2004) Application of a distributed hydrological model and weather radar observations for flood management in the upper Tone River of Japan. Hydrological Processes 18, 3119-3132

Zhang, J. and Qi, Y. (2010) A real-time algorithm for the correction of bright band effects in radar-derived QPE. Journal of Hydrometeorology 11, 1157-1171. 